\title{
Band pass filter comparison of Hairpin line and square open-loop resonator method for digital TV community
}

\author{
Budi Prasetya $^{1}$, Yuyun Siti Rohmah ${ }^{2}$, Dwi Andi Nurmantris ${ }^{3}$, Sarah Mulyawati ${ }^{4}$, Reza Dipayana \\ ${ }^{1}$ School of Electrical Engineering, Telkom University, Indonesia \\ 2,3,4,5 School of Applied Science, Telkom University, Indonesia
}

\section{Article Info \\ Article history: \\ Received Aug 20, 2019 \\ Revised Dec 11, 2019 \\ Accepted Jun 22, 2020}

\section{Keywords:}

Band pass filter

Digital TV

Hairpin-line

Square open-loop resonator

TV broadcasting

\begin{abstract}
The selection of the right filter design method is a very important first step for a radio frequency engineer. This paper presents the comparison of two methods of band pass filter design using hairpin-line and square open-loop resonator. Both methods were applied to obtain filter designs that can work for broadcasting system in digital television community. Band pass filter was simulated using design software and fabricated using epoxy FR-4 substrate. The results of simulation and measurement shown return loss value at $27.3 \mathrm{~dB}$ for hairpin line band pass filter and 25.901 for square open-loop resonator band pass filter. Voltage standing wave ratio parameter values were 1.09 and 1.1067 for hairpin line and square open-loop band pass filter respectively. The insertion loss values for the Hairpin line band pass filter and square open-loop band pass filter were 0.9692 and near $0 \mathrm{~dB}$, respectively. Fractional bandwidth, for hairpin line band pass filter, was $6.7 \%$ while for square open-loop band pass filter was $4.8 \%$. Regarding the size, the dimension of square open-loop resonator was approximately five times larger than hairpin-line band pass filter. Based on the advantages of the hairpin line method, we recommend that researchers choose the filter for digital TV broadcasting.
\end{abstract}

This is an open access article under the CC BY-SA license.

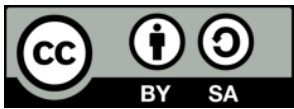

\section{Corresponding Author:}

Yuyun Siti Rohmah,

School of Applied Science,

Telkom University,

Jl. Telekomunikasi, Terusan Buah Batu, Bandung 40288, Indonesia.

Email: yuyunsitirohmah@telkomuniversity.ac.id

\section{INTRODUCTION}

Television broadcasting in Indonesia have begun to be held. With digital broadcasting, the quality of images and sound received by viewers in comparison to the analog one is now much better without any shaded images or all forms of noise. In addition, saving bandwidth usage property on digital broadcasting is a special consideration from the government to replace all analog TV broadcasting to digital one. Started in 2012, Indonesia issued the Regulation of Communication and Information Minister, Number 05 of 2012, applied the digital video broadcasting-terrestrial second generation (DVB-T2) standard which is a improvement of the DVB-T standard issued in 2007[1]. Terrestrial digital television broadcasting uses VHF/UHF radio frequencies as well as analog broadcasting, but with a digital content format. By considering the Regulation of Communication and Information Minister, Number 17 of 2013, spectrum used for digital television broadcasting is at $478-694 \mathrm{MHz}$.

One of the important devices used in television broadcasting system is band pass filter (BPF). It is used to take a signal from $f_{1}$ to $f_{2}$ and reject the smaller frequency than $f_{1}$ and frequency greater than $f_{2}$ [2]. The ideal filter must have null insertion loss at the passband, very high attenuation at the stopband, and linier phase respon at the passband [3]. Many researches of band pass filter had been proposed such as in [4], it presented 
a novel approach for first order chebyshev parallel coupled BPF resonant at $1 \mathrm{GHz}$. Also, in [5], it presented a novel technique in designing the switchable dual-band BPF for WiMAX and wireless LAN applications. Then in [6], a simple is used to design a dual band BPF using split ring resonator. And another paper is Multi-wideband microstrip Spiral BPF that is presented in [7].

Researchs on band pass filter (BPF) using hairpin-line method has also previously been carried out for various applications. In reference [8] and [9] a microstrip compact band pass filter for wireless local area network used a hairpin resonator. Another application was proposed in [10] microstrip band pass filter with hairpin resonator method for reverse frequency in the band-3 Long Term Evolution. This filter used chebyshev response and substrate duroid RT-5880. The research of hairpin-line method was combined with other technique as in [11], it used a square groove technique and gave the capability in suppression of spurious response. Another paper in [12], proposed hairpin microstrip band pass filter using an interdigital structure with the smaller parallel coupled lines than previously designed microstrip BPF of this type. In [13], filter was integrated with a harmonic suppression circuit based on quarter-wavelength short stubs. Narrowband band pass filter proposed in [14] used 5 elements of square resonator with the folded coupled-line for S band application, and it resulted in the smaller size than conventional hairpin. Hairpin-line band pass filter with dual band has also been widely considered such as in $[15,16]$. The effect of the filter order on the performance of the filter itself has been investigated in [17]. It showed the effect of shape of frequency responses such as on higher order of filter elements sharpening the selectivity of frequency response.

Besides the hairpin line method, other methods such as square open-loop resonators have been developed in research to design band pass filters. Paper [18] described a configuration for realization of canonical microstrip elliptic function narrow-band band pass filter. In paper [19], filter had smaller relative bandwidth and steeper attenuation slope. Another square open-loop resonator in [20], it proposed microstrip square open-loop resonators using surface mount capacitors. Another research in [21] dual-band band pass filter with dual mode novel perturbation element using was proposed and resulted in flexibility in tuning dual-mode characteristic and a compact structure. Paper [22] presented dual-mode BPF using the degenerate modes of a meander square ring structure printed on the high-permittivity substrate. Loading element was used to design narrow BPF using open-loop square resonators, that suited with an easier due to its compact size and versatility [23]. And also, in [24], BPF is proposed using a new compact stub-coupled microstrip square open-loop.

We are pioneering a digital TV community at Telkom University in Bandung, with the highest priority being to design and implement our own devices. The part of the device that we designed and implemented was BPF. As an alternative to design, we use two methods, namely hairpin-line and square open-loop resonator. In this paper, we compared two methods BPF design. The purpose of the comparison is so that researchers can choose the right filter type, when viewed in terms of the dimensions of the filter, insertion loss and return loss that occur, VSWR and fractional bandwidth. Both methods were applied to obtain filter designs that can work at frequencies of $470-862 \mathrm{MHz}$ for DVB-T2 application. Band pass filter can be implemented in both transmitter and receiver of broadcasting television system.

\section{RESEARCH METHOD}

The elementary configuration of the microstrip as shown in Figure 1. The microstrip contain a dielectric substrate with dielectric constant $\varepsilon_{r}$ and its substrate height $h$, above and below it is coated with a conductor, usually copper, with thickness $t$. When viewed from its construction, the upper conductor is called a line, there we form a channel with width $W$, while the bottom conductor is called a ground plane.

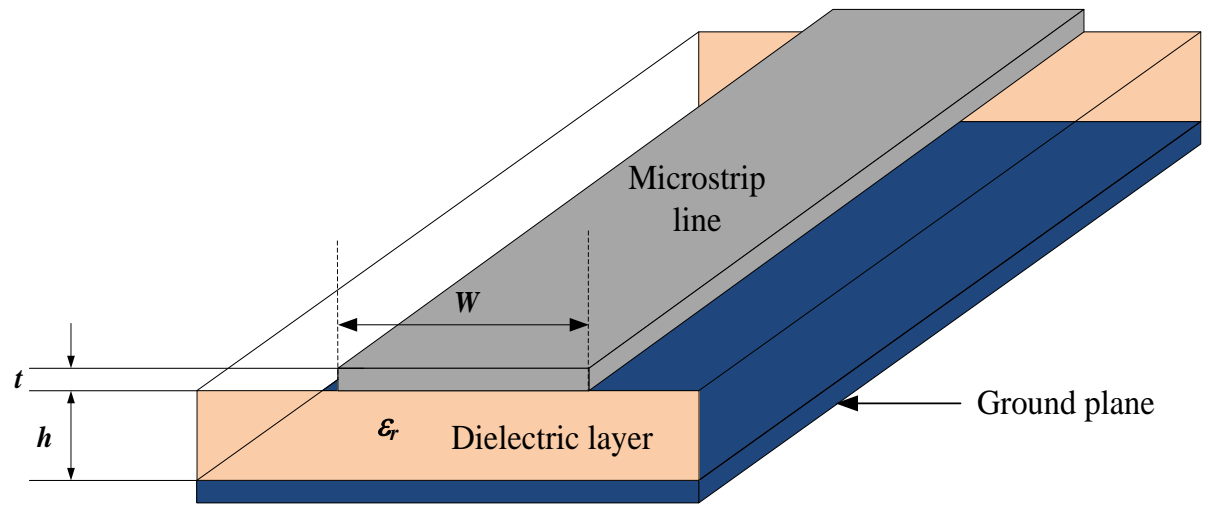

Figure 1. The basic configuration of the microstrip 


\subsection{Calculation for the band pass filter order}

Response filter of filter design in this paper used butterworth filter response that has a transfer function for insertion loss $L_{A r}$ at the cutoff frequency $\Omega_{c}$ as given by (1). A lowpass filter response was transformed to a band pass response that had a passband response as (2). The fractional bandwidth $(F B W)$ was determined by (3). The (4) was used to determine the order of a butterworth lowpass prototype, a specification commonly in the minimum stopband attenuation $L_{A S}$ at omega $(\Omega)=\Omega_{s}$ greater than one [25].

$$
\begin{aligned}
& \left|s_{21}(j \Omega)\right|^{2}=\frac{1}{1+\Omega^{2 n}} \\
& \Omega=\frac{\Omega_{c}}{F B W}\left(\frac{\omega}{\omega_{0}}-\frac{\omega_{0}}{\omega}\right) \\
& F B W=\frac{\omega_{2}-\omega_{1}}{\omega_{0}} \\
& n \geq \frac{\log \left(10^{0.1\left(L_{A S}\right)}-1\right)}{2 \log \Omega_{s}}
\end{aligned}
$$

\subsection{Synthesis of $\frac{W}{h}$}

The resonator width calculation of both methods has a dielectric constant value of 4.6 and a substrate thickness of $1.6 \mathrm{~mm}$ and characteristic impedance $\left(Z_{r}\right)$ of $50 \mathrm{ohms}$. The resonator width value can be determined using (5) and (6) [25].

$$
\begin{aligned}
& \frac{W}{h}=\frac{8 e^{A}}{e^{2 A}-2} \\
& A=\frac{Z_{r}}{60}\left\{\frac{\varepsilon_{r}+1}{2}\right\}^{0.5}+\frac{\varepsilon_{r}-1}{\varepsilon_{r}+1}\left\{0.23+\frac{0.11}{\varepsilon_{r}}\right\}
\end{aligned}
$$

\subsection{Calculation for the band pass filter order}

There is a dielectric influence caused by air and substrate to make the structure not homogeneous. The use of the relative dielectric constant is to determine the characteristic resistance. Relative dielectric constants can be considered as the dielectric constants of $a$ homogeneous medium replacing air and substrate medium with $h$ (substrate height), $W$ (thickness of microstrip) and $\varepsilon_{r}$ (dielectric constant) on microstrip channels to determine effective dielectric constants determined by using the (7), (8) and (9) [25].

$$
\begin{aligned}
& a=1+\frac{1}{49} \ln \left[\frac{(u)^{4}+\left(\frac{u}{52}\right)^{2}}{(u)^{4}+0.432}\right]+\frac{1}{18.7} \ln \left[1+\left(\frac{u}{18.1}\right)^{3}\right] \\
& b=0.564\left(\frac{\varepsilon_{r}-0.9}{\varepsilon_{r}+3}\right)^{0.053} \\
& \varepsilon_{r e}=\frac{\varepsilon_{r}+1}{2}+\frac{\varepsilon_{r}-1}{2}\left[1+\frac{10}{W / h}\right]^{-a b}
\end{aligned}
$$

Table 1 presents the dimension values obtained from both of hairpin-line methods and the square open-loop resonator based upon the equation used in the reference. From the calculation obtained, the desired parameter was not reached and for that reason, optimization was performed by changing the dimensional parameters of the two methods used. Table 2 shows the final simulation dimension of two methods used for fabrication. The dimensions of the square open-loop resonator band pass filter were five times greater than the hairpin-line one.

Band pass filter comparison of Hairpin line and square open-loop resonator method for... (Budi Prasetya) 
Table 1. Band pass filter optimization

\begin{tabular}{|c|c|c|c|c|c|c|c|c|}
\hline \multirow[b]{2}{*}{ Parameters } & \multicolumn{4}{|c|}{ Hairpin Line } & \multicolumn{4}{|c|}{ Square Loop } \\
\hline & *Calcul. & $\begin{array}{c}* * \text { Optim. } \\
1 \\
\end{array}$ & $\begin{array}{c}\text { Optim. } \\
2 \\
\end{array}$ & $\begin{array}{c}\text { Optim. } \\
3 \\
\end{array}$ & Calcul. & $\begin{array}{c}\text { Optim. } \\
1 \\
\end{array}$ & $\begin{array}{c}\text { Optim. } \\
2\end{array}$ & $\begin{array}{c}\text { Optim. } \\
3 \\
\end{array}$ \\
\hline $\mathrm{Wt}(\mathrm{mm})$ & 2.95 & 2.85 & 2.8 & 2.9 & 2.95 & 1.4 & 1.3 & 1.3 \\
\hline $\mathrm{Wr}(\mathrm{mm})$ & 2.95 & 2.85 & 2.8 & 2.9 & 2.95 & 1.4 & 1.3 & 1.3 \\
\hline $\operatorname{Lr}(\mathrm{mm})$ & 8 & 9 & 8 & 8 & 8 & 20 & 20 & 30 \\
\hline $\mathrm{Lt}(\mathrm{mm})$ & 75 & 80 & 47.6 & 47.6 & 75 & 59 & 60 & 60 \\
\hline $\begin{array}{l}\text { Distance of Resonator } S_{12} \\
\text { and } S_{34}\end{array}$ & 1.875 & 1 & 0.3 & 0.4 & 1.875 & 0.35 & 0.3 & 0.27 \\
\hline Distance of Resonator $\mathrm{S}_{23}$ & 3.1 & 1.5 & 0.8 & 1.2 & 3.1 & 1.125 & 1.3 & 1.25 \\
\hline Return Loss (dB) & 1.871 & 19.7 & 42.5 & 33.8 & 0.176 & 0.182 & 13.336 & 27.344 \\
\hline Insertion Loss (dB) & 27.927 & 14.29 & 2.026 & 2.026 & 73.826 & 73.819 & 5.594 & 4.712 \\
\hline VSWR & 9.318 & 1.178 & 1.015 & 1.041 & 98.899 & 95.4 & 1.549 & 1.09 \\
\hline FBW $(\%)$ & - & 1.05 & 23.27 & 9.6 & - & 5.7 & 5.59 & 6 \\
\hline
\end{tabular}

Table 2. Dimension of hairpin line band pass filter

\begin{tabular}{lcc}
\hline \multicolumn{1}{c}{ Variable } & Hairpin Line $(\mathrm{mm})$ & Square Loop $(\mathrm{mm})$ \\
\hline Supply Width $(\mathrm{Wt})$ & 2.9 & 1.3 \\
Resonator Width (Wr) & 2.9 & 1.3 \\
Resonator Length $(\mathrm{Lr})$ & 8 & 30 \\
Supply Length $(\mathrm{Lt})$ & 47.6 & 60 \\
Distance of Resonator $\mathrm{S}_{12}$ and $\mathrm{S}_{34}$ & 0.4 & 0.27 \\
Distance of Resonator $\mathrm{S}_{23}$ & 1.2 & 1.25 \\
\hline
\end{tabular}

Figures 2 and 3 illustrate a band pass filter using the hairpin line method and square open-loop resonator respectively. The filters order was four, where the dimensions of this filter are written in Table 2. Figure 4 show the simulation results of the return loss parameters of the two methods. Return loss is the ratio between the power transmitted to the power reflected, while $S_{11}$ is the ratio of the wave reflected to the incoming wave, so the magnitude of the return loss is equal to the absolute of $S_{11}$. The tuning optimization was done from the calculation of the previous dimensions by increasing the value of the width of the feedline, the width of the resonator, and the distance between the resonators. The value of return loss at $666 \mathrm{MHz}$ frequency was 33,847 dB for the hairpin line method and 27,344 dB for the square open-loop method.

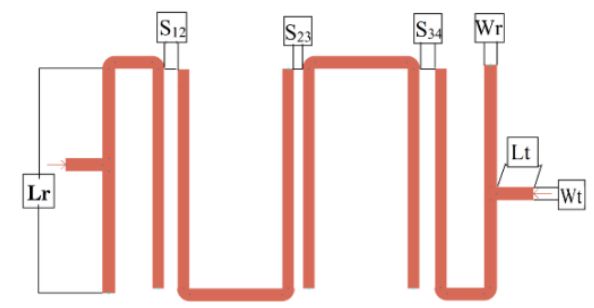

Figure 2. Simulation design of hairpin-line band pass filter

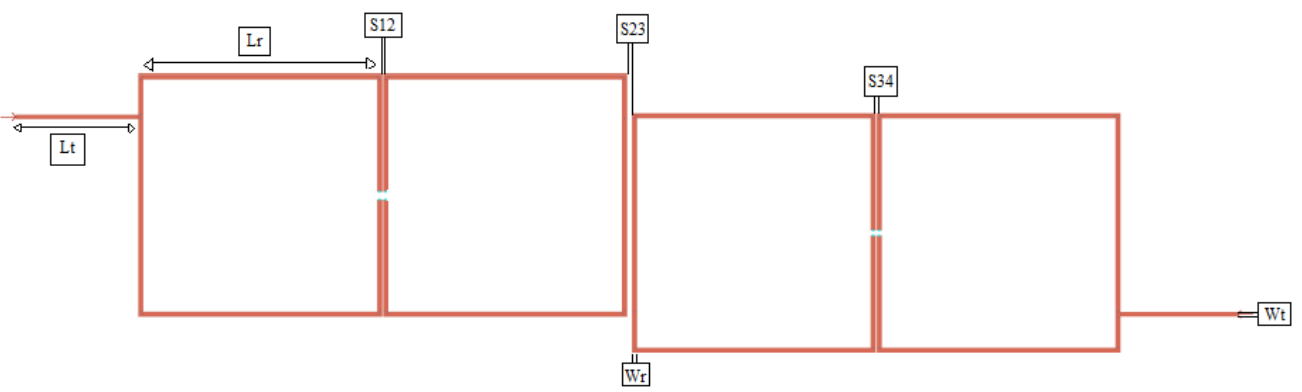

Figure 3. Simulation design of square open-loop resonator band pass filter 


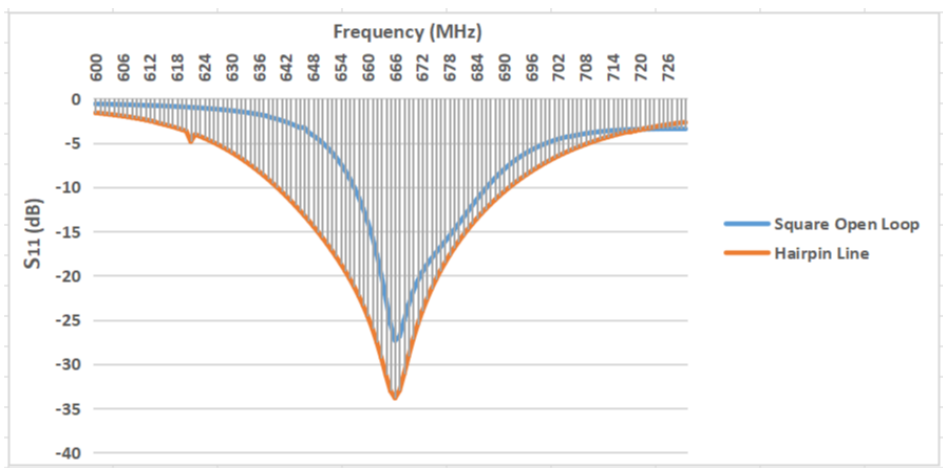

Figure 4. Return loss from simulation result of hairpin-line BPF method and square open-loop resonator method

Figure 5 shows the $S_{21}$ parameter value as a function of frequency for each hairpin line and square open-loop resonator method. Figure 5 also shows that based on simulation, a BPF with a square open-loop resonator method has sharper response characteristics than the hairpin line method. In Figure 5, the fractional bandwidth of hairpin line BPF and square open-loop resonator were about $9.6 \%$ and $6 \%$. Band pass filter of two methods at frequency $666 \mathrm{MHz}$ was categorized as narrowband BPF.

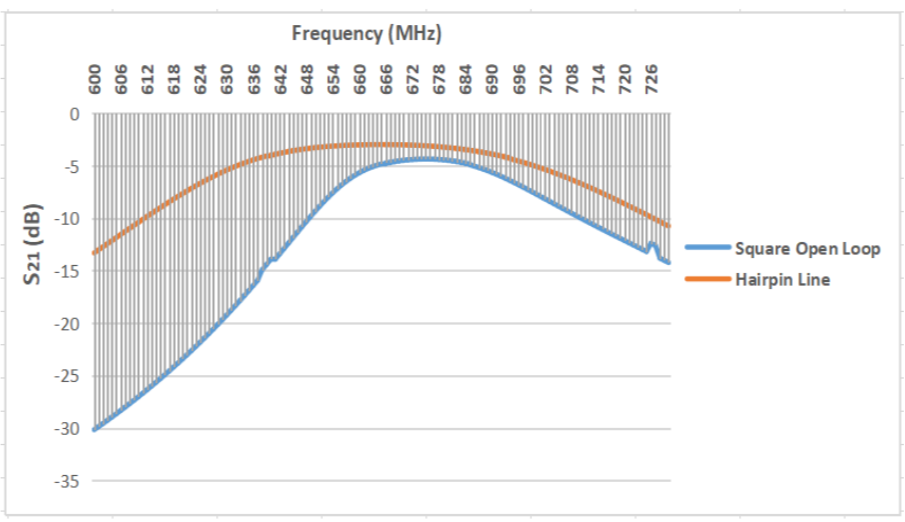

Figure 5. The curve of $S_{21}$ parameter from simulation result of hairpin-line BPF method and square open-loop resonator method

\section{RESULTS AND DISCUSSION}

The design of both hairpin-line and square open-loop resonator BPF was simulated by the advanced design system software and it was fabricated using substrate FR-4 Epoxy. The connector SMA 50 ohm was used to be soldered with line and a ground plane. Figure 6 and Figure 7 show the Fabrication of the hairpin-line band pass filter and square open-loop resonator BPF respectively. The dimension of square open-loop resonator BPF was about $300 \times 100 \mathrm{~mm}^{2}$, five times wider than hairpin line band pass filter was abaout $100 \times 60 \mathrm{~mm}^{2}$.

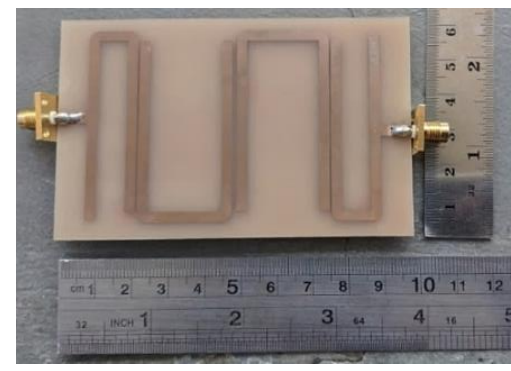

Figure 6. Fabrication of hairpin-line BPF method

Band pass filter comparison of Hairpin line and square open-loop resonator method for... (Budi Prasetya) 


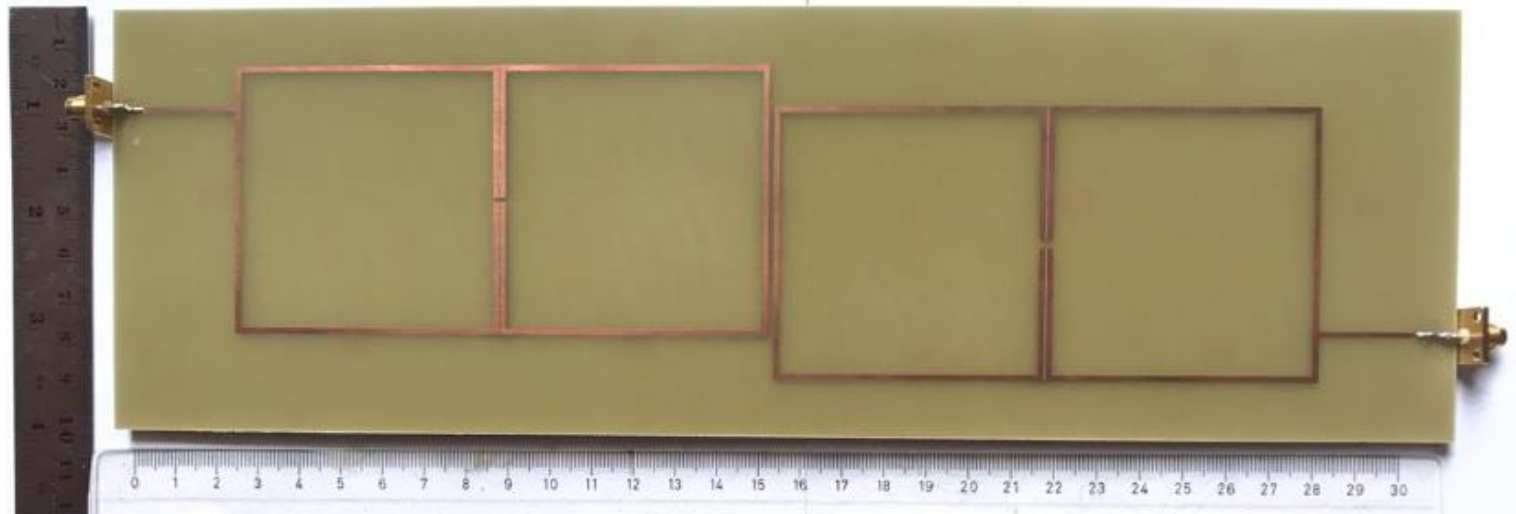

Figure 7. Fabrication of square open-loop resonator BPF method

\subsection{Measurement of BPF return loss}

The measurement of return loss and insertion loss used network analyzer (NA). Return loss measurements can be seen in the S11 parameter. The value of return loss is obtained by taking the absolute value of S11 parameter. The higher value of the return loss, the smaller the power reflected to the source. Thus, the maximum power transfer will occur. Figure 8 shows the return loss value of 27,340 dB for band pass filter with the hairpin-line method.

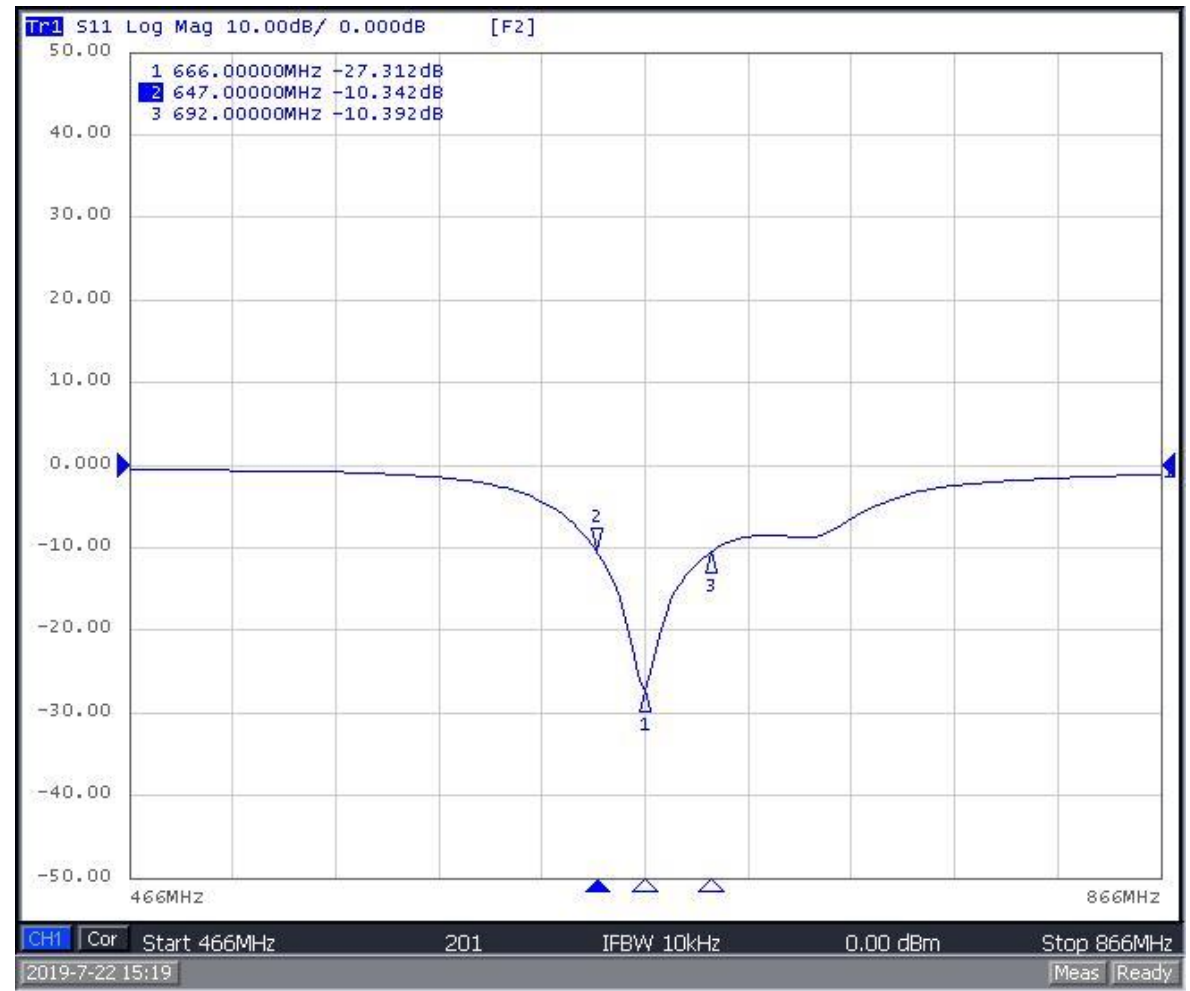

Figure 8. Return loss measurement result of hairpin-line BPF method

Figure 9 shows measurement result of return loss for band pass filter with the square open-loop resonator method about 25,901 dB. From the S11 parameter measurement results, it obtained the fractional bandwidth of approximately $6.7 \%$ for hairpin-line method and $4.8 \%$ for square open-loop method. From the value of fractional bandwidth, square open-loop resonator had smaller Bandwidth compared to hairpin-line band pass filter. 


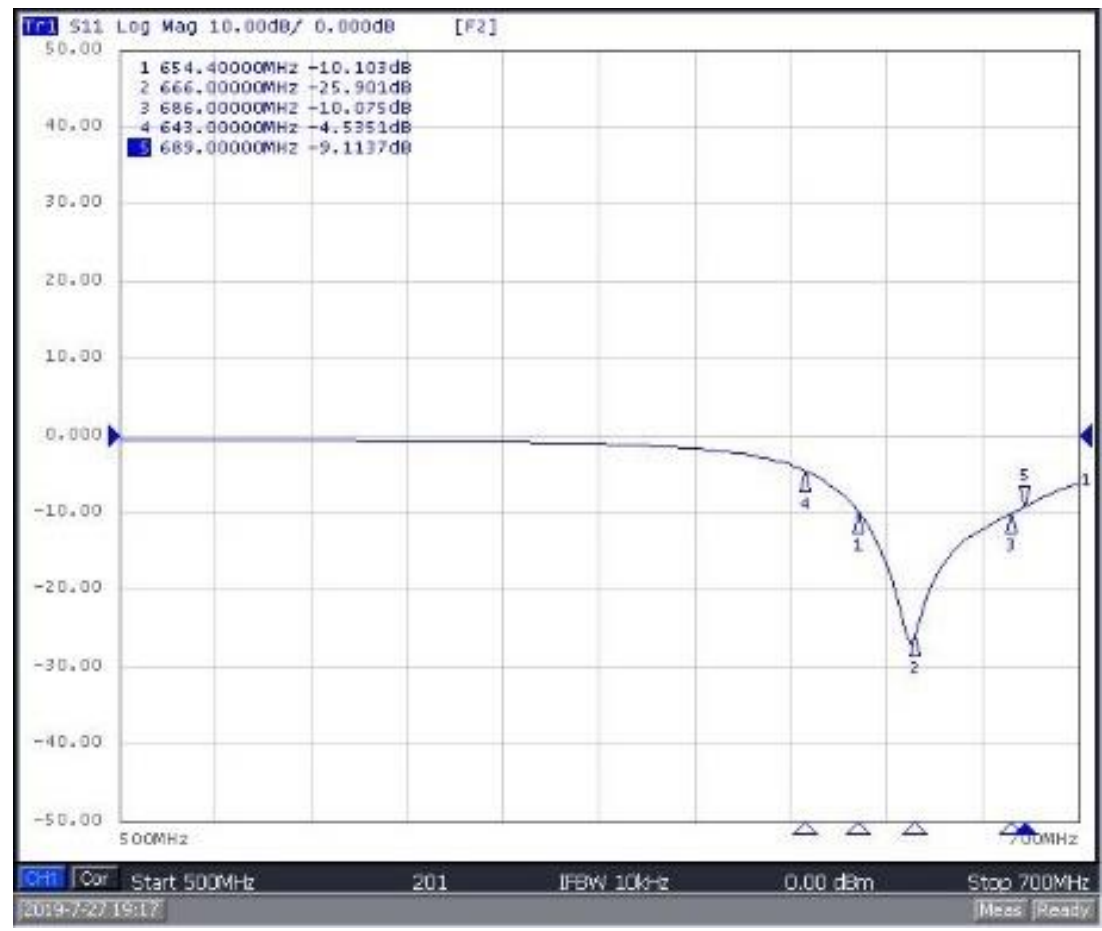

Figure 9. Return loss measurement result of square open-loop resonator BPF method

\subsection{Measurement of BPF insertion loss}

Insertion loss measurements can be seen in the $S_{21}$ or $S_{12}$ parameter, which shows the frequency response of the signal transmitted from port 1 to port 2 or from port 2 to port 1 . Figure 10 and Figure 11 show the power gain curve as a function of frequency, resulting from the measurement of parameters $S_{21}$ or $S_{12}$. Figure 10 and Figure 11 also show the comparation of insertion loss measurement of two methods.

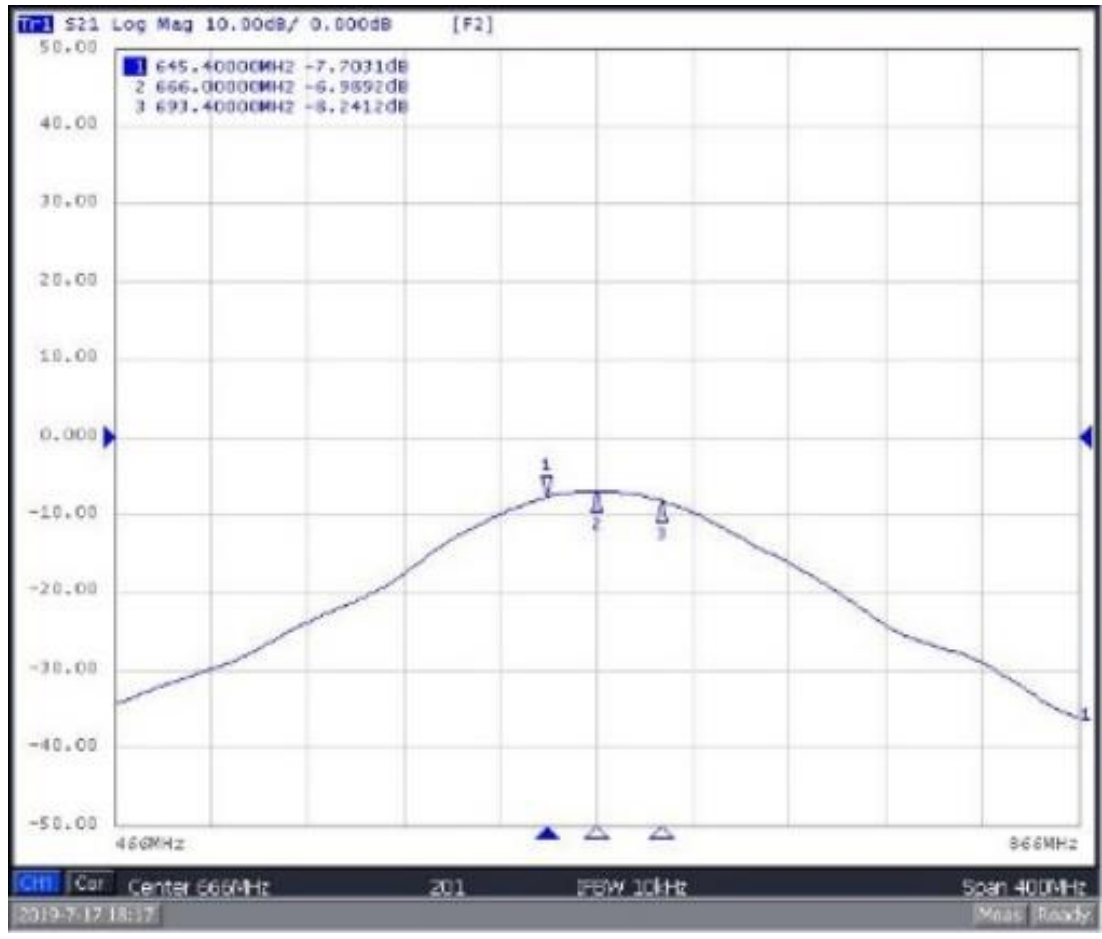

Figure 10. insertion loss measurement of hairpin-line BPF method 
The value of insertion loss is obtained by taking the absolute value of gain (or $S_{2 l}$ in $\mathrm{dB}$ ) minus 6.02 $\mathrm{dB}$. The reading absolute value of $S_{21}(\mathrm{~dB})$ from NA must be reduced by $6,02 \mathrm{~dB}$, because if without the filter insertion and matching conditions between source and load, then $S_{21}$ at the operating frequency is $-6.02 \mathrm{~dB}$. Based on the measurement results at the center frequency of $666 \mathrm{MHz}$, the insertion loss value obtained $0.9692 \mathrm{~dB}(6.9892-6,02) \mathrm{dB}$ for hairpin-line BPF and near $0 \mathrm{~dB}(5.9511-6.02) \mathrm{dB}$ for square open-loop resonator BPF. Ideally, the insertion loss value is $0 \mathrm{~dB}$, but because there are some losses component of the filter, the ideal value of insertion loss is difficult to be achieved.

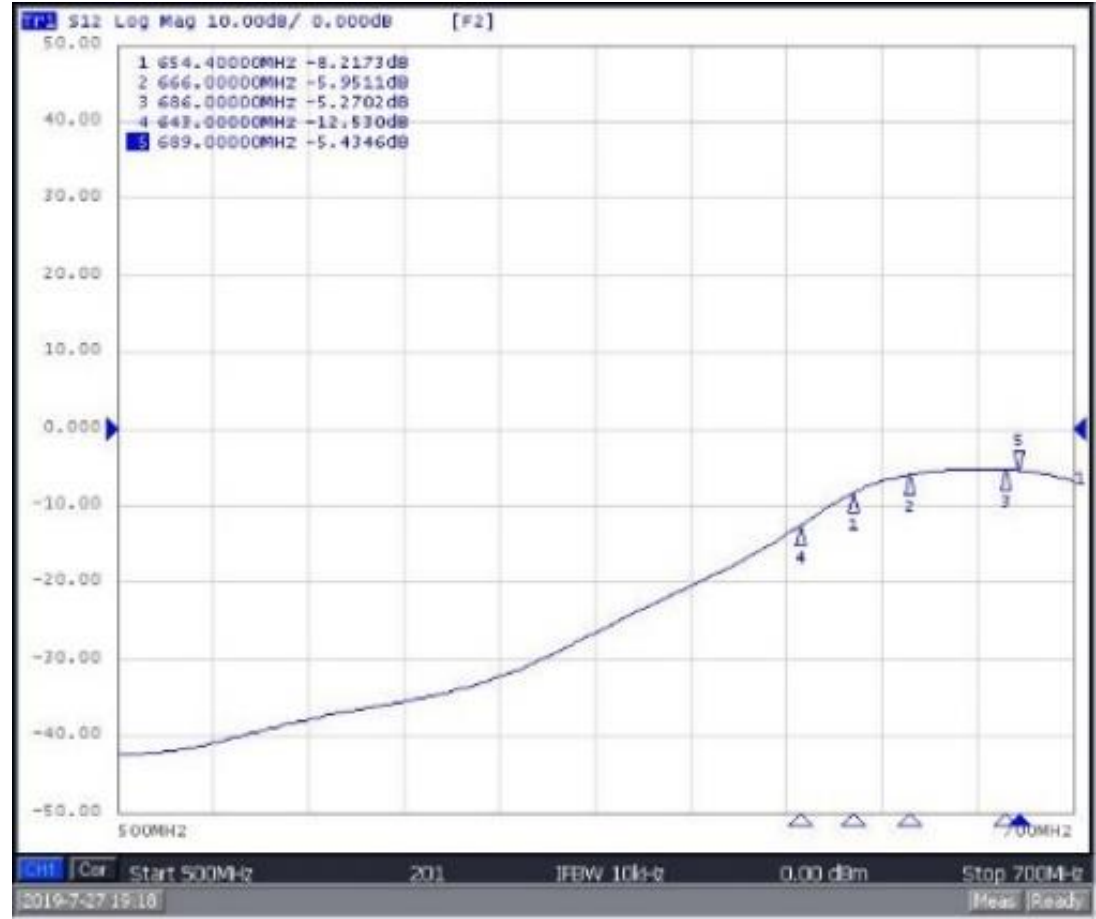

Figure 11. Insertion loss measurement of square open-loop resonator BPF method

Table 3 shows the result comparison of two band pass filters using hairpin-line and square open-loop resonator methods. For band pass filter parameter such as return loss and voltage standing wave ratio (VSWR), the performance of hairpin-line band pass filter was found better than that of square open-loop resonator although the difference in value between the two was not so significant. Fractional bandwidth parameter in both systems gave the value categorized as narrowband filter.

Table 3. Parameter comparison of hairpin line and square loop method band pass filter

\begin{tabular}{ccccc}
\hline \multirow{2}{*}{ Parameters } & \multicolumn{2}{c}{ Hairpin Line } & \multicolumn{2}{c}{ Square Loop } \\
\cline { 2 - 5 } & Simulation & Measurement & Simulation & Measurement \\
\hline Centre Frquency (MHz) & 666 & 669.5 & 666 & 670 \\
Return Loss (dB) & 33.8 & 27.3 & 27.344 & 25.901 \\
Insertion Loss (dB) & - & 0.9692 & - & $\approx 0$ \\
VSWR & 1.04 & 1.09 & 1.090 & 1.1067 \\
Fractional BW (\%) & $9.6 \%$ & $6.7 \%$ & $6 \%$ & $4.8 \%$ \\
Dimension $\left(\mathrm{mm}^{2}\right)$ & $100 \times 60$ & $100 \times 60$ & $300 \times 100$ & $300 \times 60$ \\
\hline
\end{tabular}

\section{CONCLUSION}

Based on the simulation and measurement of BPF with Hairpin Line and Square open-loop resonator method, parameter values such as return loss, VSWR, insertion loss and fractional bandwidth met the desired initial specifications. The resulting return loss was $27.3 \mathrm{~dB}$ for BPF hairpin line and 25.901 for BPF square open-loop resonator. VSWR parameter values were 1.09 and 1.1067 for BPF hairpin line and square open-loop resonator respectively. For the Return Loss and VSWR parameters, the BPF designed by 
using the Hairpin Line method had a better performance than the square loop though the value was not significantly different. However, for fractional bandwidth (FBW), the square loop method produced a smaller value than the hairpin equal to $4.8 \%$, while the FBW with the hairpin method was found at $6.7 \%$. This fractional bandwidth is corresponding with the narrowband category that has a range below $10 \%$. This BPF is designed on the frequency of TV channels in Indonesia. The insertion loss values for the Hairpin line and square loop method were found at $0.9692 \mathrm{~dB}$ and near $0 \mathrm{~dB}$, respectively. This was in view of a trade off between fractional bandwidth and insertion loss. When the desired fractional bandwidth value is small, the insertion loss value obtained will be large. In the dimension comparison, square open-loop resonator had a size about five times wider than hairpin-line band pass filter. Thus, in dimension parameter, the hairpin-line band pass filter was found more effective than square open-loop resonator band pass filter.

\section{ACKNOWLEDGEMENTS}

We would like to thank Telkom University for funding this research. It is included in the basic and applied research of batch 1 of 2019 based on the decree of the Vice Chancellor for Research and Student Affairs number: KWR4.111/PNLT3/PPM/2019.

\section{REFERENCES}

[1] M. D. Arza, Y. S. Rohmah and R. Anwar, "Design and Realization of Linear Array Triangular Patch Microstrip Antenna for Digital Television," 2018 International Conference on Control, Electronics, Renewable Energy and Communications (ICCEREC), Bandung, Indonesia, pp. 226-230, 2018.

[2] D. W. Astuti, Juwanto and M. Alaydrus, "A bandpass filter based on square open loop resonators at $2.45 \mathrm{GHz}$," 2013 3rd International Conference on Instrumentation, Communications, Information Technology and Biomedical Engineering (ICICI-BME), Bandung, pp. 147-151, 2013.

[3] D. M. Pozar, Microwave Engineering. New York, NY, USA: John Wiley and Sons, Inc, 1998.

[4] Z. A. A. Hassain, A. A. Al-behadili, and A. R. Azeez, "First order parallel coupled BPF with wideband rejection based on SRR and CSRR," Telecommunication, Computing, Electronics and Control, vol. 17, no. 6, pp. 2704-2712, 2019.

[5] M. Mabrok, Z. Zakaria, Y. E. Masrukin, and T. Sutikno, "Switchable dual-band band pass filter based on stepped impedance resonator with U-shaped defected microstrip structure for wireless applications," Telecommunication, Computing, Electronics and Control, vol. 17, no. 2, pp. 1032-1039, 2019.

[6] P. Chauhan and A. Vidyarthi, "Dual band band-pass filter using cascaded split ring resonator," $20173 \mathrm{rd}$ International Conference on Advances in Computing,Communication \& Automation (ICACCA) (Fall), Dehradun, pp. 1-5, 2017.

[7] M. Sujatha, R. Ramana Reddy, N. K. Darimireddy and B. Ramamohan, "Multi Wideband Hexagonal-Spiral Microstrip Band-Pass Filter for Wireless Applications," 2018 IEEE Indian Conference on Antennas and Propogation (InCAP), Hyderabad, India, pp. 1-4, 2018.

[8] S. M. Kayser Azam, M. I. Ibrahimy, S. M. A. Motakabber and A. K. M. Zakir Hossain, "A Compact Bandpass Filter Using Microstrip Hairpin Resonator for WLAN Applications," 2018 7th International Conference on Computer and Communication Engineering (ICCCE), Kuala Lumpur, pp. 313-316, , 2018.

[9] A. K. Pandey and R. K. Chauhan, "Miniaturized dual-band BPF for WiMax/WLAN applications," 2016 IEEE 1st International Conference on Power Electronics, Intelligent Control and Energy Systems (ICPEICES), Delhi, pp. 1-4, 2016.

[10] M. Fadhil, H. Wijanto and Y. Wahyu, "Hairpin line bandpass filter for 1.8 GHz FDD-LTE eNodeB receiver," 2017 International Conference on Radar, Antenna, Microwave, Electronics, and Telecommunications (ICRAMET), Jakarta, pp. 134-136, 2017.

[11] K. Srisathit, J. Tangjit and W. Surakampontorn, "Miniaturized microwave bandpass filter based on modified hairpin topology," 2010 IEEE International Conference of Electron Devices and Solid-State Circuits (EDSSC), Hong Kong, pp. 1-4, 2010.

[12] I. Islam, N. Islam and M. Haque, "A miniaturized interdigital hairpin microstrip bandpass filter design," 2013 International Conference on Informatics, Electronics and Vision (ICIEV), Dhaka, pp. 1-4, 2013.

[13] M. Yousefi, H. Aliakbarian and R. Sadeghzadeh, "Design and integration of a high-order hairpin bandpass filter with a spurious suppression circuit," 2015 Loughborough Antennas \& Propagation Conference (LAPC), Loughborough, pp. 1-4, 2015 .

[14] F. Darwis, A. Setiawan and P. Daud, "Performance of narrowband hairpin bandpass filter square resonator with folded coupled line," 2016 International Seminar on Intelligent Technology and Its Applications (ISITIA), Lombok, pp. 291-294, 2016.

[15] H. Liu, B. Ren, F. Liu, X. Guan, P. Wen and Z. Ma, "Dual-Band High-Temperature Superconducting Bandpass Filter Using Dual-Mode Hairpin Ring Resonator," in IEEE Transactions on Applied Superconductivity, vol. 26, no. 7, pp. 1-4, 2016.

[16] A. K. Pandey and R. K. Chauhan, "Miniaturized dual-band BPF using hairpin loaded interdigital structure," 2016 International Conference on Computing, Communication and Automation (ICCCA), Noida, pp. 1618-1621, 2016.

[17] A. Munir and T. Praludi, "Characteristic of narrowband hairpin BPF as influence of number of its elements," 2015 International Conference on Quality in Research (QiR), Lombok, pp. 39-42, 2015. 
[18] J. S. Hong and M. J. Lancaster, "Canonical microstrip filter using square open-loop resonators," in Electronics Letters, vol. 31, no. 23, pp. 2020-2022, 1995.

[19] J. Liu, X. Zhu, L. N. Quyen and C. You, "High-suppression three-pole tunable band-pass filter using square openloop resonator," 2011 IEEE International Symposium on Antennas and Propagation (APSURSI), Spokane, WA, pp. 3365-3368, 2011.

[20] L. Ledezma and T. Weller, "Miniaturization of microstrip square open loop resonators using surface mount capacitors," WAMICON 2011 Conference Proceedings, Clearwater Beach, FL, pp. 1-5, 2011.

[21] X. Shi, X. Xi and D. Wu, "A dual-mode dual-band bandpass filter with novel perturbation element using open loop resonator," 2014 International Symposium on Antennas and Propagation Conference Proceedings, Kaohsiung, pp. 179-180, 2014.

[22] C. Chen, Y. Lin and H. Chen, "Miniaturized Dual-Mode Bandpass Filter Using Meander Square Ring Resonator," 2007 IEEE Conference on Electron Devices and Solid-State Circuits, Tainan, pp. 777-780, 2007.

[23] A. V. Mannam and Y. R. Veeranki, "Design of narrowband band pass filter using open-loop square resonators with loading element," Indian J. Sci. Technol., vol. 9, no. 47, pp. 1-9, 2016.

[24] R. K. Maharjan, B. Shrestha, and N. Y. Kim, "Compact microstrip square open-loop band pass filter using open stub," Electron. Lett., vol. 48, no. 6, p. 333, 2012.

[25] J. S. Hong and M. J. Lancaster, Microstrip Filters for RF/Microwave Applications. New York, NY, USA: John Wiley and Sons, Inc, 2001.

\section{BIOGRAPHIES OF AUTHORS}

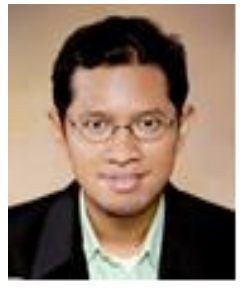

Budi Prasetya completed his undergraduate studies in 2001 at the School of Technology Telkom, Bandung, Indonesia. In that year also began as an assistant Lecture at the same school. In 2006 finished his graduate studies at the Bandung Institute of Technology and started to become a lecturer at the Telkom Telkom University. His current research interests include wireless communication, IF-RF processing, rotate modulation, adaptive modulation and coding, resource allocation in OFDMA (Orthogonal frequency division multiple access) systems, and digital TV.

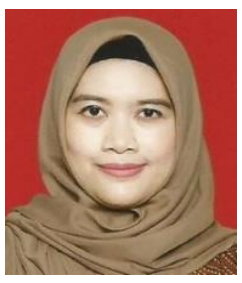

Yuyun Siti Rohmah received master in telecommunication engineering from Telkom University, Bandung in March 2010, she joined as Lecture in Diploma of Telecommunication Engineering since 2010. Her Research interest in RF transmission of wireless communication, wireless channel modeling, and channel coding for $5 \mathrm{G} / 6 \mathrm{G}$.

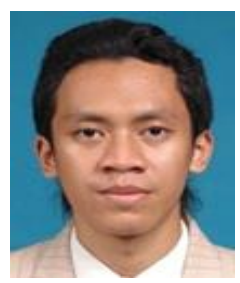

Dwi Andi Nurmantris received master in telecommunication engineering from Telkom University, Bandung in March 2014. Since 2011, He joined as a Lecture in The Diploma of Telecommunication Technology, School of Applied Science, Telkom University. His research interest are Mobile and Wireless Communication Systems, Microwave Passive device and Antenna design.

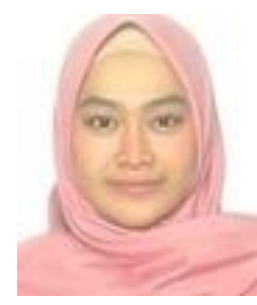

Sarah Mulyawati was a Diploma Telecommunication Engineering student at Telkom University. In this study as a research assistant. Currently she has completed her study program.

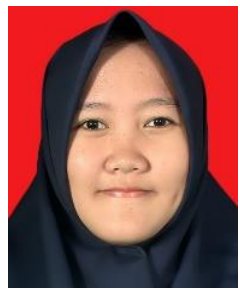

Reza Dipayana was a Diploma Telecommunication Engineering student at Telkom University. In this study as a research assistant. Currently she has completed her study program. 